\title{
EL GOBIERNO DE LAS POBLACIONES: AUGUSTO ORREGO LUCO Y LA CUESTIÓN SOCIAL EN CHILE
}

\author{
César Leyton Robinson \\ FOUCH \\ Universidad de Chile \\ Email: cleyton@odontologia.uchile.cl \\ ORCID iD: https://orcid.org/0000-0002-2825-6097
}

Recibido: 16 mayo 2019; Aceptado: 18 junio 2019

Cómo citar este artículo/Citation: Leyton Robinson, César (2020), "El Gobierno de las poblaciones: Augusto Orrego Luco y la Cuestión Social en Chile", Asclepio, 72(1): p297. https://doi.org/10.3989/asclepio.2020.06

RESUMEN: Partiendo de dos textos fundamentales del médico chileno Augusto Orrego Luco: La cuestión social (1897) y su Discurso de toma de posesión de su cargo de presidente de la Sociedad Médica (1895), se analiza las propuestas que este autor desarrollo sobre el papel de la ciencia en el gobierno de las poblaciones. Se presta atención a conceptos, como el de raza vagabunda en relación con la cuestión social, y racial, en el Chile de finales del siglo XIX y se identifican influencias científicas como el determinismo biológico y la teoría de la degeneración.

PALABRAS CLAVE: Augusto Orrego Luco; Cuestión social; degeneracionismo; ciencia y regulación social; Chile.

THE GOVERNING OF POPULATIONS: AUGUSTO ORREGO LUCO AND THE SOCIAL QUESTION IN CHILE

ABSTRACT: Based on two essential texts by Chilean doctor Augusto Orrego Luco - La cuestión social (The Social Question, 1897) and his Discurso de toma de posesión de su cargo de presidente de la Sociedad Médica (Speech on taking up his position as president of the Medical Society, 1895) - we analyse this author's proposals regarding the role of science in governing populations. The analysis focuses on concepts such as the vagabond race in relation to the social and racial question in late-19th-century Chile, and identifies scientific influences such as biological determinism and the theory of degeneracy.

KEY WORDS: Augusto Orrego Luco; social question; degenerationism; science and social regulation; Chile.

Copyright: @ 2020 CSIC. Este es un artículo de acceso abierto distribuido bajo los términos de la licencia de uso y distribución Creative Commons Reconocimiento 4.0 Internacional (CC BY 4.0). 


\section{INTRODUCCIÓN}

La línea de pensamiento y de intervención social inaugurada en Chile por Benjamín Vicuña Mackenna (1831-1886) encontrará continuación y desarrollos precisos de la mano de otros intelectuales liberales. El higienismo urbano fue dando paso a un discurso que trasciende los espacios de la ciudad para ocuparse, de una manera más genérica, del gobierno de las poblaciones. La visión que las elites tienen, y pretenden transmitir, de las poblaciones populares adquiere, en muy buena medida, una fundamentación científica en la que el determinismo biológico desempeña un papel primordial y de cuyo análisis nos ocuparemos en las páginas que siguen tomando como objeto de nuestro estudio los aportes de una de las figuras más destacadas de la medicina chilena del cambio de siglo: Augusto Orrego Luco (1849-1933).

Si el abogado, político e historiador Vicuña Mackenna diseñó y ejecutó una tecno-utopía urbana en su calidad de Intendente de la ciudad de Santiago (Leyton y Huertas, 2012), será un médico político el que desarrollará todo un discurso de defensa e higiene social. Orrego Luco, médico y psiquiatra, cultivó la literatura y el periodismo político, siendo redactor de El Ferrocarril y El Mercurio, así como director de la Revista Chilena y fundador de la Revista de Santiago. Miembro del partido liberal, fue diputado, presidente de la Cámara de Diputados (1886-1888) y ocupó varias carteras ministeriales ${ }^{1}$. Pero lo que más nos interesa destacar aquí es que Orrego Luco fue uno de los más destacados representantes de lo que Ricardo Cruz Coke ha denominado "oligarquía médica chilena", para ilustrar que "unos pocos destacados profesores controlaban todos los altos cargos públicos médicos y de salud del Estado, en los ministerios, Parlamento, instituciones de higiene, Universidad, Facultad de Medicina, Sociedad Médica, Revista Médica" (Cruz-Coke, 1995, p. 463). Del mismo modo que otros destacados médicos chilenos, como José Joaquín Aguirre (1822-1901), Orrego Luco, fue profesor y director, en 1871, de la Escuela de Medicina de la Universidad de Chile y presidente de la Sociedad Médica de Chile en 1895 (Goic, 1992, p.10; Larraín, 2002). Sus cargos políticos, antes mencionados, hacen de Orrego Luco uno de los médicos más influyentes de su época.

Merece la pena señalar que esta "oligarquía médica" puede identificarse en otros contextos. Probablemente la influencia de la medicina francesa, tan evi- dente en los médicos chilenos del siglo XIX², al menos hasta la Guerra del Pacífico (1879-1883) cuando la medicina y el ejército vivieron una fuerte modernización prusiana, se extendió también a la organización del poder médico. En Francia José Mateo Buenaventura Orfila (1787-1853), catedrático de Medicina Legal y decano de la Facultad de Medicina de París, llegó a configurar un entramado médico-político en apoyo de la "monarquía liberal" de Luis Felipe de Orleans (1725-1785) que ilustra perfectamente las dinámicas que estamos apuntando. Desde su puesto de decano Orfila creó una "aristocracia científica" mediante la que controló la sanidad y la salud pública francesa y que, de algún modo, complementó el papel de la "aristocracia financiera" descrita por Karl Marx (18181883) como la fracción de la burguesía que comprende a "banqueros, reyes de la bolsa, reyes de los ferrocarriles, propietarios de las minas de carbón y de hierro, propietarios de las tierras" (Marx, 1850/ 2008). Una "aristocracia científica" que, en total convivencia con la clase dominante, ocupó importantes parcelas de poder y de influencia y colaboró, como poseedora de los conocimientos científicos necesarios, en el control social que el régimen político liberal precisaba (Huertas, 1988).

Volviendo a la figura de Augusto Orrego Luco, otros autores han matizado y profundizado en los conceptos que estamos manejando, al utilizar el término intelligentsia médica (Illanes, 2010), un selecto grupo de médicos cercanos al higienismo que, a partir de su discurso sanitario sobre las enfermedades y sus propuestas de defensa de la ciudad y de la raza chilena, penetraron el mundo social y político. Estos médicos adquirieron un estatus social cercano a la tradicional elite y varias vacantes en el parlamento y ministerios, en su mayoría, bajo el alero del partido liberal (Cruz Coke, 1995). Un sitial que posibilitó al Estado un naciente poder tecnocrático que se esforzó en ofrecer las soluciones que necesitaba la emergente república, la cual todavía no podía superar su origen productivo agrario, casi colonial, quedándose al margen del progreso industrial que inducía el cambio de siglo.

De la amplia producción científica y literaria de Orrego Luco, dos textos resultan especialmente significativos para nuestro análisis. Por un lado, La cuestión social fue originariamente una colección de artículos que aparecieron en el periódico porteño $L a$ Patria a lo largo de 1884 para ser publicados más tarde, en 1897, de manera conjunta. Por otro, el im- 
portante discurso de toma de posesión de su cargo de presidente de la Sociedad Médica, que fue transcrito y reproducido en la Revista Médica de Chile, en 1895. Se trata de dos textos fundamentales para entender no solo el pensamiento médico-social de su autor sino también para valorar de qué medida se va construyendo un discurso que tiende a constituir una nueva forma de administración y gubernamentalidad de los sectores populares, a través de nuevos dispositivos o formas de control, relacionadas con una mirada socio-biológica de estos grupos relegados. Teorías científicas basadas en un determinismo hereditario y/o ambiental que explicaría tanto sus patologías físicas y mentales, como su miseria social.

\section{LA RAZA VAGABUNDA Y LA CUESTIÓN SOCIAL}

Orrego Luco muestra su preocupación por lo que denomina la "raza vagabunda". Los cambios del modelo productivo dieron lugar a la aparición de una población errante que se convierte en un fenómeno fundamental de la cuestión social:

Esa raza vagabunda es la expiación del régimen económico y social a que nuestras haciendas han estado sometidas, régimen que solo podía sostenerse mientras la dificultad de comunicación mantuviera separadas la población urbana y la rural y que naturalmente debía caer hecho pedazos el día que se estableciera una corriente entre las ciudades y los campos (Orrego, 1897, p. 39.)

Se trata de sujetos no productivos y no siempre movilizables como fuerza de trabajo: los vagabundos, gentes "sin juramento de fidelidad", sin ataduras, portadores de una libertad de movimientos que les sitúan al margen de la norma. La vida errante sin oficio y sin domicilio fijo implica una fisura más en la pretendida estabilidad de la sociedad burguesa, en el equilibro de la jerarquía social, y supone, en definitiva, una desviación social y un problema de orden público. Tras el fin del Ancien Régime el nuevo estado liberal facilita y canaliza la movilidad de la población siempre que ésta esté suficientemente codificada: el problema no está en el campesino que marcha a trabajar a la cuidad, o en el obrero que circula de una fábrica a otra, sino en el que rechaza la fábrica (o en el menor que huye de la escuela) (Gaudemar, 1979).

Es sabido que desde Karl Marx y su XVIII Brumario de Luis Bonaparte (Marx, 1853/ 2011), los vagabundos han sido considerados integrantes del lumpen- proletariat y, con las crisis económicas, del "ejército industrial de reserva" (armée de réserve). Sin embargo, pienso que el rasgo definitorio del vagabundo tiene que ver, fundamentalmente, con su peligrosidad social, con su asimilación a la otredad, a una representación de "nómada extranjero" que propicia un sentimiento de inseguridad porque interfiere y amenaza el buen orden burgués. En este sentido, resulta oportuna la definición ofrecida por Robert Castel cuando escribe:

Pero, ¿quiénes son en realidad los vagabundos? Peligrosos depredadores que acechan en el borde del orden social, que viven del robo y amenaza la propiedad y la seguridad a la gente? Esta es la forma en que se presentan, y que justifica un tratamiento inusual: ellos han roto el pacto social -trabajo, familia, moralidad, religión- y son enemigos del orden público (Castel, 1995, p.97).

Desarraigo, transgresión y desorden confluyen en la figura del vagabundo, símbolo antiburgués tan atractivo como inquietante. Se hace necesario actuar sobre esa errancia no canalizada, mediante una codificación estricta de los desplazamientos. Determinadas instituciones reguladoras de entradas y salidas entran en juego: cárcel, reformatorio, manicomio, workhouse, etc., de tal modo que encierro y moralización; criminalización y patologización, constituyen ejes fundamentales de la estrategia de domesticación del vagabundo con el fin de que acepte e interiorice las normas establecidas y de que se integre en el sistema productivo (Fecteau, 2004; Huertas, 2008). Lo crucial era saber por qué el vagabundo era un "otro" distinto, peligroso, perseguido, enjuiciado y condenado (Araya, 1999; Góngora, 1966).

En dicho proceso de patologización, algunos autores han llegado a afirmar que la medicina francesa de la segunda mitad del siglo XIX consideró de manera unánime que "todos los vagabundos eran enfermos mentales" (Durou, 1966) y que el fenómeno del vagabundaje "converge en el dominio intrínseco de la patología mental" (Beaune, 1983). El problema es, sin embargo, más complejo, pues intervienen factores sociales y culturales locales que hacen que las relaciones entre vagabundaje y enfermedad mental (en particular la llamada fuga disociativa) sea más visible en unos contextos que en otros (Hacking, 1998); por ejemplo, al contrario que en Inglaterra y en el resto del mundo sajón, en Francia existe una amplia producción sobre les aliénés voyageurs. Médicos de renombre, como el mismísimo Charcot (1825- 1893), participaron en el debate sobre si la "enfermedad del 
vagabundaje" era debida a la histeria o a la epilepsia (Huertas, 2014 ; Vaschetto, 2010).

Llama la atención que Orrego Luco, alienista de formación francesa e, incluso colaborador de Charcot, no aluda en ningún momento a relaciones entre nomadismo y locura. Resulta obvio que sus intereses son otros, ofreciendo un discurso más propio de un estadista y de un médico social que de un psiquiatra clínico.

El nomadismo, pues, rompe con el modelo económico, pero para nuestros objetivos, lo interesante es ver cómo es considerado como un mal endógeno objeto de la mirada médica. Para Orrego:

(...) desde hace cuarenta o cincuenta años principió a aparecer el peón forastero, esa masa nómade, sin familia, sin hogar propio, sin lazo social, que recorre las haciendas en busca de trabajo. Esa masa flotante no echa raíces en ninguna parte, no tiene nada que la ligue, y constituye la fuerza y la debilidad de Chile, su miseria adentro y su grandeza afuera (Orrego, 1897, p. 37).

Las causas del nomadismo tienen que ver, según Orrego, con cambios en el clima y en la alimentación de la población:

Esa masa enorme y peligrosa ha salido del rancho del inquilino, ha principiado á salir hace cuarenta o cincuenta años, precisamente en la misma fecha en que los efectos del cambio de clima se principiaron a sentir, en que en el desequilibrio entre la alimentación y las condiciones atmosféricas se principió a acentuar, en que también las precipitaciones se principiaron a ser fáciles, rompiendo las vías públicas que vivían las haciendas (Orrego, 1897, p. 38).

Las causas mesológicas y el determinismo ambiental $^{3}$ son muy evidentes en las argumentaciones del médico chileno. De los cambios climáticos resultará una "grave y peligrosa anomalía": "la de un pueblo que habita un clima frio y tiene la alimentación vegetal de los países tropicales, y que está, por consiguiente, fatalmente condenados al abuso de las bebidas alcohólicas para poder sostener su lucha con el clima" (Orrego, 1897, p. 25).

La importancia otorgada a la alimentación es fundamental, una alimentación propia de culturas asiáticas y mesoamericanas que el médico lamenta pues considera el origen de muchos males:

Bajo esa misma base se han levantado las sociedades antiguas, los grandes y dóciles imperios del Asia y América, desarrollándose sus castas a la sombra de los mismos principios económicos. Y con la misma razón que se ha dicho, que el arroz ha hecho la China, el ragi ha hecho a la India, el maíz a los grandes imperios de Méjico y los Incas, podemos decir que nuestro alimento va desarrollando todo un régimen social, de clases y castas, régimen de honda división que tiene como base el bajo precio del jornal (Orrego, 1897, p. 32).

Y será, precisamente, la alimentación vegetal la que explicaría, siempre según Orrego, la "notable fecundidad de nuestra raza" (Orrego, 1897, p. 29). Una fecundidad que es comparada con la de los pueblos asiáticos, inferiores y degenerados; pero también con la propia manera de ser de las clases populares, envueltas "en una atmósfera de enervante indiferencia, en esa resignación silenciosa de los pueblos orientales, sin iniciativa, sin esfuerzo por mejorar su condición" (Orrego, 1897, p. 34). Esto es, la antítesis de dinamismo y la iniciativa que exigen las elites liberales dispuestas a modernizar el país.

Se va constituyendo así una población subalterna que debe ser dirigida. Los nuevos asalariados o jornaleros pueden ser libres, deben salir de su condición de esclavo feudal agrario; pero, aunque en otro contexto, se sigue fundamentando una naturaleza inferior de estas razas, destinadas a seguir siendo mano de obra para el proyecto comercial e industrial que se avecina. Esta población "asiática", si no se controla adecuadamente, pone en peligro el sistema económico.

No cabe duda de que la masa campesina errante que abunda por todas las fronteras de la nación, que emigra a otras naciones, supone un problema de distribución territorial. El médico Orrego Luco piensa que esa masa agraria poblará las ciudades, generando problemas sanitarios y políticos. Por lo tanto, introducirá en su análisis el lenguaje de la prevención y las estadísticas, sobre todo, en las que tienen que ver con la reproducción y la distribución de la población. Siendo estas causadas, mayoritariamente, por el alto índice de mujeres. Esta mayoría de mujeres, se explica, por la emigración de muchos trabajadores fuera del país:

Es decir que vive fuera de los pueblos una población casi cuatro veces mayor que la que encierran sus ciudades (...) Este es el primer rango que dibuja la diversidad de regiones, acentuada por otro hecho de gravísima importancia: la proporción en que se encuentran los dos sexos. (...) Si ese predominio femenino no es debido ni al mayor nacimiento de mujeres, ni a una mortalidad mayor entre los hombres, solo puede ser el resultado de una emigración que arrastra las fuerzas vivas del país (Orrego, 1897, p. 16) 
La modernización ha provocado cambios materiales, que pueden traer consecuencias sociales. El desarrollo de los medios de comunicación, caminos urbanos, carreteras a centros económicos, que unen los centros agrarios y urbanos, hace que esta población nómade comience a transformarse en un posible habitante de las ciudades, lo que se convierte en un motivo de inquietud, un peligro que comienza a acechar a las elites. La ostentosidad que vive, puede convertirse en una atracción de aspiraciones para esta masa, que no tiene derechos económicos, ni políticos. Los (nuevos) bárbaros, como plantea Orrego Luco, pueden tener ambiciones que atenten contra el monopolio de la riqueza.

La facilidad de los transportes y sobre todo los establecimientos bancarios, ha hecho posible la construcción de habitaciones elegantes y suntuosas, y lleva a los campos casi todos los refinamientos de la vida urbana, presentando al inquilino un nuevo ideal, una nueva y deslumbradora aspiración. Esa brusca revelación de la riqueza ha debido lógica y necesariamente producir un sacudimiento moral muy semejante al que experimentaron los bárbaros al ver aparecer de una manera repentina los esplendorosos monumentos del imperio (Orrego, 1897, p. 40.)

Es evidente la llamada a los sectores políticos, que todavía no se dan cuenta de la formación del proletariado, para unirse en la defensa social, para conservar la organización social a pesar de la modernización industrial:

No creemos necesario ahondar más aún en este problema, porque creemos haber bosquejado sus contornos con suficiente claridad para poder decir que estamos envueltos en una cuestión social amenazadora y peligrosa, que reclama la más seria atención del estadista (...) para poder decir que el proletariado se está constituyendo á nuestra vista, y que delante de nosotros se desorganiza la familia en los ranchos y se destruye el equilibrio de los sexos (Orrego, 1897, p. 45.)

Por eso resulta urgente, en el sentir de Orrego, intervenir con medidas higiénicas y regulación social que terminen con el nomadismo. La labor no es fácil: "Ahora, si esa masa es una masa nómade, errante, que va de rancho en rancho, de aduar en aduar, ¿cómo se puede pensar seriamente en inspirarle hábitos de higiene y economía, en desarrollar su inteligencia y levantar su moral?" (Orrego, 1897, p. 51.)

La forma de hacerlo no es otra que el disciplinamiento de esta población errante en torno a la industria, organizarla en torno al trabajo, incorporarla a una clase social: "Lo primero es fijar esa masa, aglomerarla alrededor de un trabajo organizado, ha- cerla entrar en las clases sociales, presentarle un núcleo de condensación, y ese núcleo es el trabajo fijo del establecimiento y de la industria" (Orrego, 1897, p. 51.)

Pero para "fijar" a esa masa itinerante es preciso procurarle un ambiente adecuado. Conseguir una masa asalariada, saludable y productiva es uno de los objetivos básicos de la medicina social liberal (Rosen, 1985). Así se expresa Orrego cuando afirma que:

En las condiciones de vida que atraviesa la masa de esas poblaciones está, pues, el secreto del peligroso mal que las invade, que debilita nuestra fuerza productora y amenaza el desarrollo nacional. (Orrego, 1897 , p. 17)

Higiene y moralización de las clases populares serán elementos indispensables para la mejora de las condiciones de vida y, sobre todo, para la nueva forma de organización social que se pretende:

\footnotetext{
Material y moralmente la atmósfera del rancho es una atmósfera malsana y disolvente, y que no solamente presenta al estadista el problema de la mortalidad de los párvulos, sino también el problema más grave todavía de la constitución del estado civil, de la organización fundamental de la familia; problema formidable en que hasta ahora no se ha fijado la atención y que esta llamado a hacer una peligrosa aparición en un término acaso no lejano (Orrego, 1897, p. 35.)
}

Esta organización social tiene elementos biopolíticos nada desdeñables: matrimonios y parentescos, vinculación sanguínea claramente definida, formando vínculos familiares y territoriales que lo identifiquen con el sedentarismo, abandonando la circulación como gañanes y su reproducción de "huacherío" (huérfanos o expósitos) sin vínculo social. El mero higienismo queda completado por un depurado discurso político sanitario que se elabora en pleno proceso de reforma urbana y de discusión sobre cómo enfrentar la cuestión social y el control de la población. El Estado liberal debe intervenir.

Economía e higiene aparecen como los elementos de una alternativa política que debería sacar al proletariado de su inferioridad, dejando atrás los vicios que lo condenaban a ser una masa etnológicamente primitiva:

Una masa aguijoneada por las implacables exigencias de la vida no puede consagrarse á su mejoramiento intelectual, no puede pensar en economías ni higiene, está condenada á vegetar en el trabajo y á que los vicios materiales devoren (Orrego, 1897, p. 51.) 
Pero lo más importante es que este programa no podrá cumplir su objetivo de intervención, si no se articula un Estado de control. La doctrina del laissez aller, laissez faire puede ser aplicada a la economía, pero no al control de las poblaciones. Si la máxima liberal del laissez faire, laisser passer implica una aparente despolitización del Estado, para asegurar la libertad económica, política y social, la realidad es que la libertad de mercado se hace rápidamente compatible con un estado interventor en lo político que garantice la "tranquilidad social" y la producción. Orrego Luco no tiene dudas al respecto:

Desde luego, en presencia de esa amenazadora y grave situación, la doctrina de la indiferencia impasible, del laissez aller, laissez faire, está juzgada de una manera inexorable. Al amparo de esa doctrina imprevisora se ha desarrollado precisamente la situación que deploramos, y que de una manera natural se agravaría si permitiéramos que continúe desenvolviendo sus efectos.

Necesitamos, pues, intervenir para ayudar con mano vigorosa el establecimiento de nuevas condiciones económicas y nuevas condiciones morales, que nos saquen de la atmosfera en que las bajas capas sociales ahora se sienten asfixiadas (Orrego, 1897, p. 46)

El programa higienista no solamente quiere acabar con las malas condiciones sanitarias del bajo pueblo, sino también con la peligrosidad que implica su descontento social. Los criminales agrarios pueden emigrar a la ciudad y convertirse en la concretización del temor de la elite, atentando contra sus intereses de organización y de sistema económico. Un diseño, que no termine en una coerción vehemente por parte del Estado, sino que ofrezca soluciones sin recurrir a las viejas formas de autoridad y soberanía de la muerte:

Si a esto se añade una aplicación más seria de los principios de la higiene, el establecimiento de la vacunación obligatoria, un servicio hospitalario para la asistencia de los párvulos y una organización menos estrecha de la caridad social, se tendrán en su conjunto las medidas primordiales que reclama de los hombres de Estado este problema que más adelante puede exigir soluciones de un carácter áspero y violento (Orrego, 1897, p. 53.)

Así pues, el programa higienista no solamente resuelve los problemas sanitarios y garantiza la reproducción de la fuerza de trabajo. También previene la violencia social que puede detonar en los sectores populares. Los reformadores como Vicuña Mackenna y Orrego Luco, planifican esta defensa de la ciudad y de la población, siendo el Estado el llamado a cumplir esta misión. La peligrosidad social de las poblaciones que emigran a la ciudad generan un temor político que hay que resolver, que hay que predecir. Los pobres pueden levantarse como criminales, como delincuentes (el salvaje de origen agrario) dispuestos a cobrar venganza (Salinas, 1986). El problema no es nuevo pues, como advierte Orrego Luco, situaciones similares se dieron antes de la Guerra del Pacífico de 1879 poniendo de manifiesto el peligro de la rebelión social convertida en una "marea negra" arrolladora e imparable, a la vez que alude -en una línea de pensamiento lombrosiana que más adelante abordaremos- a los instintos atávicos de la criminalidad salvaje:

Y la posibilidad de esas situaciones no puede ser una quimera para el que recuerda el estado social que atravesamos cuando estalló la guerra hace cinco años. Veíamos entonces que la cuestión social principiaba á hacer su sombría y tremenda aparición.

Las doctrinas mas disolventes flotaban en la atmósfera; los arrabales se presentaban á desafiar la fuerza pública en el corazón mismo de Santiago; partidas de bandoleros recorrían los campos; la policía estaba al acecho de incendiarios. $Y$ aquella marea negra iba subiendo, haciéndose cada día más amenazadora y más audaz, y dejando entrever más claramente la perspectiva de esos trastornos sociales que no gobiernan las ideas sino las ferocidades salvajes del instinto (Orrego, 1897, p.53.)

Tal como había ocurrido en otras naciones -y como ocurre hoy día- el crimen y la inestabilidad social genera desconfianzas al capital:

Se había entrado en un círculo vicioso de que la desagraciada Irlanda, á pesar de tantos esfuerzos, parece no poder salir. El crimen crea la desconfianza, y la desconfianza, engendrando la miseria, provoca al crimen. El capital no viene á fecundar el suelo porque no hay seguridad, y la seguridad falta porque el capital falta. Era, pues, necesario aprovechar los momentos en que existía todavía la confianza, en que no había aparecido todavía el crimen agrario que dio origen al circulo vicioso de la Irlanda; ese momento en que unos solos pocos hombres previsores entreveían la cuestión social que se acercaba (...) Esa inseguridad de la tenencia es la base, como ya hemos dicho, de la cuestión irlandesa, y esa inseguridad de la tenencia también se presenta en nuestros campos. Allá produjo como primer efecto la emigración y el trabajador vagabundo - efectos que aquí también ha producido, - después los White boys, los steel boys, los black feet y los ribonmen, es decir, el terror y el crimen agrario. Y por último los fenianos, que á todos los peligros de aquella situación vinieron á añadir las dificultades de complicaciones exteriores (Orrego, 1897, p. 53).

Los gañanes criminales, la población vagabunda delictiva (bandoleros, salteadores rurales, cuatreros) 
es objetivo de las medidas de seguridad. Se trata de grupos que pueden arribar a la ciudad y que es preciso detener situando los muros que los contengan, bulevares, defensas. Para Vicuña Mackenna, la creación de una policía moderna es la solución, pero no deja de llamar la atención el papel de los propios sectores populares en la formación de los nuevos cuerpos de seguridad del Estado:

No tenemos la razón que nos place atribuirnos cada día para maldecir i desconocer una administración reciente $i$ especial, gracias a la cual vivimos en mediana paz i confianza en medio del profundo desorden que trabaja las regiones inferiores del pueblo, en cuyo seno elegimos alternativamente nuestros esclavos y nuestros custodios (Vicuña, 2013 [1875], p.129).

Esclavos y custodios, trabajadores y policías, reprimidos y represores, todos procedentes de una misma clase social desfavorecida.

Sin embargo, para Orrego, la criminalidad, como más tarde veremos, se puede enfrentar con criterios científicos. La ciencia debe estar al servicio del Estado, pero para desempeñar tal misión se precisó investigación y tecnologías de medición que faciliten la información y el conocimiento necesario. Las estadísticas y los estudios de población de Quetelet (1796-1874); la degeneración de Morel (1809-1873), la criminología de Lombroso (1835-1909), etc., irán conformando el marco en el que construir una normativa biológica y social que identifique e integre a los aptos y excluya a los residuos sociales incapaces de incorporarse al modelo productivo.

\section{BIOLOGÍA, ECONOMÍA Y POBLACIÓN. LA MEDICIÓN DE LA POBLACIÓN}

La percepción de territorios inseguros, en los que debe conformarse una población acorde con el modelo productivo, comenzó a plantearse en los procesos de urbanización europea de fines del siglo XVIII, cuando la marginalidad urbana sufrió el "gran encierro", en términos de Foucault, en hospitales generales, lazaretos, hospicios para pobres, lugares que mezclaban marginalidad urbana, prostitutas, venéreos, locos y anormales físicos (Peset, 1987). En Chile, es Manuel de Salas (1754-1841) -reformador social ilustrado de comienzos del siglo XIX- quién abre la discusión sobre la situación de la población marginal, proponiéndole al Imperio español, todavía vigente en la administración política, solucionar uno de los problemas geoestratégicos fundamentales que le preocupaba a la corona: revertir la situación de "despoblación" que vivía la región de Chile. Como plantea Vázquez García, las vacunaciones no eran solamente un tema de filantropía médica, el peligro de la extinción de súbditos e indígenas, terminaría con la burocracia y la tributación al imperio, y abría la posibilidad de ocupación de otras potencias europeas de las colonias españolas de ultramar (Vázquez, 2009). Incluso medidas sanitarias realizadas por las primeras expediciones médicas hispanas, como la de Xavier Balmis (1803-1810) buscaron resolver estas situaciones. La temprana vacunación de súbditos en Chile, por el sacerdote Pedro Manuel Chaparro de la congregación de San Juan de Dios, en las campañas de inoculación de viruela en 1805, no escaparía a estas políticas de cuidado de la población colonial (Ramírez, 2002; Cruz-Coke, 1995, p. 249).

La creación del primer hospicio para pobres planteado por Salas, pretendía cumplir el objetivo de mejoramiento sanitario con el fin de preservar el crecimiento de la población:

La pobreza extrema, la despoblación asombrosa, los vicios, la prostitución, la ignorancia y todos los males que son efecto necesario del abandono de tres siglos, hacen a este fértil y dilatado país la lúgubre habitación de cuatrocientas mil personas, de las que los dos tercios carecen de hogar, doctrina y ocupación segura, cuando podrían existir diez millones sobre más de diez mil leguas cuadradas de fácil cultivo (Grez, 1995, p. 45).

La relación entre vida, economía y población es, pues, un tema que está muy presente en los ilustrados o incipientes liberales de la primera mitad del siglo XIX. La continuidad del debate sobre las condiciones de la población se vuelve central en la segunda mitad de la centuria, cuando el modelo de crecimiento necesita de una mano productiva. Orrego Luco aborda la cuestión, pero ya no es la despoblación del territorio lo que le preocupa sino la decadencia de la raza y el envejecimiento de la población. Su reflexión se centra entonces en la emigración y en la "fecundidad de la raza", fenómenos que son identificados a través de las estadísticas, que le permiten cuantificar el problema y lamentar sus consecuencias:

No creemos que por ese camino se llegue a la despoblación del territorio, pero evidentemente estamos en presencia de un grave mal que por ahora obliga solamente a un número limitado de individuos al cruel abandono de la patria (Orrego, 1897, p. 10) 
La emigración como mal social de progreso y la fecundidad descontrolada, traerían consigo mortalidad infantil, hacinamiento, subalimentación, poniendo en peligro el futuro de la nación. Hay que encontrar, por tanto, las causas de estos males que aquejan a la población. Las preguntas sobre la relación económica, las condiciones sociales y la "forma de vida", irrumpen con fuerza en el discurso de Orrego:

¿Cuál es ese mal? ¿Dónde está la causa de esa corriente que emigra al exterior y de esa mortalidad que devora á nuestros párvulos? ¿Es la obra exclusiva de las condiciones económicas? ¿Es el resultado de dificultades sociales? (Orrego, 1897, p. 10.)

Ordenar la población en un territorio, crear las tecnologías (estadísticas) sobre la vida de las poblaciones, obtener información de cómo gobernarlas para el modelo productivo, crear una verticalidad de conducción del Estado que controle a estas poblaciones atrapadas en un mundo pasado es el secreto que busca resolver Orrego Luco. Acabar con las limitaciones que condenan la vida de esta población especie, atajar la amenaza que, en un doble sentido, representan dicha población: La que limita la vida de esa masa productora, y posteriormente, la de la peligrosidad social que desafía a los gobiernos:

En las condiciones de vida que atraviesa la masa de esas poblaciones está, pues, el secreto del peligroso mal que las invade, que debilita nuestra fuerza productora y amenaza el desarrollo nacional (Orrego, 1897, p. 17.)

Toda una tecnología (bio) estadística, médica y criminológica se va desarrollando con el fin de identificar carencias, pero también de intervenir, conducir y someter a la población:

Uno de los más hermosos triunfos de las investigaciones científicas del siglo es haber llegado á formular las grandes leyes que dominan el movimiento social, y haber conseguido poner de manifiesto que esas leyes están sujetas á condiciones materiales que la estadísticas puede formular (Orrego, 1897, p. 18.)

La confianza absoluta en la ciencia y sus leyes, en la investigación y conformación de estándares de vida, de objetivación de los seres vivos, al modo de la historia natural y sus clasificaciones de las especies, constituye el marco de referencia. Las "leyes" estadísticas que motivan los "movimientos" de las poblaciones ofrecen una lectura sobre la voluntad de los individuos y permiten deducir, predecir y anunciar las conductas sociales. Una tecnología capaz de elaborar una "cartografía de la voluntad", que mida para el Estado las variables del comportamiento humano. Un "control a distancia”, según la expresión de Yuri Carvajal (2013), que puede identificarse en el discurso de Orrego:

Los actos individuales de mas caprichosas apariencias, que exigen un número mayor de circunstancias fortuitas para poderse producir y en que la voluntad del hombre parece dominar sin contrapeso,- están sujetos, sin embargo, á una regularidad que pone de relieve un factor extraño y superior a la simple voluntad del individuo (Orrego, 1897, p. 19.)

El médico chileno cita los trabajos de Adolphe Quételet (1796-1874) al que considera el gran descubridor de las leyes sociales (Orrego, 1897, p.19). Quételet publicó en 1835 su obra Sur l'homme et le développement de ses facultés, ou Essai de physique sociale, obra importante y pionera de la aplicación de la estadística a la sociología. Basándose en probabilidades matemáticas y partiendo de datos sobre determinadas conductas sociales (criminalidad, suicidio, locura, etc.), Quételet estudia y propone ciertos patrones de predicción de los comportamientos sociales (Quételet, 1827). La ciencia aparece, una vez más, como el fundamento de un Estado laico que desplaza a la Iglesia en la contabilidad de las personas (nacimiento y defunciones), pero también que marca los contornos de la normativización social (Sánchez, 1999). Contribución científica y política a la vez que fue recogida por Orrego Luco y aplicada a la realidad chilena:

Todos sabemos que la criminalidad obedece á las fórmulas de una estadística casi absolutamente matemática, y que es posible decir de antemano no sólo cuál será la cifra de los crímenes que se van cometer el año próximo, sino hasta su forma y hasta el instrumento con que lo van a perpetrar (Orrego, 1897, p. 19)

Medir y cuantificar la vida, su proyección, su muerte, es la función médica a desarrollar, como una fisiología, o una física social, inspirada en la estadística de Quételet. Por eso el suicidio, la fecundidad, la alimentación, la emigración y los sexos, se ordenan, como factores que prolongan o limitan en el desarrollo de las poblaciones y determinan sus conductas:

El suicidio, que á primera vista es el acto que más difícilmente se puede sujetar á leyes regulares, las respeta sin embargo, y por más temerario que parezca, se puede decir: el año próximo tantos hombres y tantas mujeres se verán arrastradas por la desesperación á una muerte voluntaria, como se puede decir el número de hombres y mujeres que se van á unir en matrimonio (Orrego, 1897, p. 20).

La construcción de fenómenos demográficos o de población, a través de fórmulas estadísticas, van con- 
figurando un sujeto, un hombre estandarizado, que Quételet denominó "hombre medio", concepto que surge en el marco de las sociedades con una alta densidad demográfica y que pretende "incluir" a la mayoría de la población "normalizada" y gobernada (Ellul, 1965).

En 1843 se funda la primera oficina Nacional de estadísticas en Chile con el objetivo de organizar censos modernos de la población. A pesar de que ya se habían instaurado algunos en la época colonial, es a partir de la iniciativa del naturalista Claudio Gay (1800-1873), cuando se moderniza y funda como institución del Estado-nación. Desde ese momento se establecen cincos censos nacionales que reflejan la política de Estado, de una administración moderna sobre la población. Contabilizar la población chilena, homogeneizarla (étnica y culturalmente) en criterios descriptivos y de integración de territorios (territorios aislados en la zona austral y las nuevas zonas mineras y agrícolas integradas en la guerra del Pacífico y en la ocupación de la Araucanía) en un proceso expansivo que se produce a lo largo de todo el siglo XIX, son las aplicaciones centrales de la información obtenida (INE, 2009).

El primer censo de 1843, que, a pesar de cambiar la visión colonialista de una población dividida en diferentes castas raciales, no cumple con los objetivos de entregar información para la administración política y económica de la nación. Sus metodologías arcaicas y su vinculación a la Iglesia, siguen arrastrando antiguas formas de conducir estas instituciones. No será hasta el censo de 1865, cuando se aplique la metodología de Quételet (INE, 2009, p. 112), y se abogue por el hombre medio chileno: la raza única. La construcción de un imaginario social, de una población homogénea, donde oficialmente no existe negritud, como en el resto de América latina, ni extranjeros subalternos, ni indígenas. La raza única es un intento por introducir una identidad nacional y por excluir a los que no representaban los valores de la modernidad.

Esto es lo interesante de la doctrina poblacional de Quételet, su búsqueda estadística de un hombre medio con ciertas características físicas, morales e intelectuales, van conformando en palabras de Sandra Caponi, "una normalidad biológica y social" (Caponi, 2013). Esta se constituye a través de la obtención de un biotipo poblacional homogenizado/higienizado; una construcción del "hombre medio" que es la que recoge Orrego Luco: la articulación entre lo físico, lo moral e intelectual y su relación con la historia y una determinada geografía. Quételet compara el promedio de altura del hombre con la vivienda (Caponi, 2013 , p. 837), para determinar que todo territorio posee su propio cuerpo, su propio tipo de individuo. Su masa corporal (según el índice de Quételet: masa/ estatura), no es sino la media que identifica a un grupo racial de población. Un modelo normativo "físicosocial" que representa al hombre medio, a la civilización.

Ahora bien, las estadísticas sobre crímenes, suicidios, locura, etc., agrupados por Quételet, permiten obtener datos de la población que se desvía del estándar del "hombre medio", por eso en los censos de población no solo se incorpora una mirada de identidad nacional, sino que se añaden la diferencia:

Por un lado, las categorías se amplían y se incorporan las sugerencias de los expertos extranjeros, que plantean lo importante de dejar explícito lo diferente, ya que eso constituye también las características generales de una población (INE, 2009, p.114).

Así, se van incorporando varios ítems de información, a partir de las influencias del método de Quételet, incluyendo datos obligatorios para el empadronamiento: nombres y apellidos, sexo, jefe de familia, estado civil, profesión, culto, lengua, conocimiento de lectura y de escritura, origen de nacimiento y nacionalidad (INE, 2009, p. 115); pero aparece también un ítem que, en cierta forma, busca identificar los niveles intelectuales de la población. La ceguera, la sordomudez, el idiotismo i cretinismo i la enajenación men$t a l^{4}$. Aunque la incapacidad física estaba considerada desde mediados del siglo XIX, hay ya un acercamiento al "desviado", al que se sale de la norma biológica y es portador de taras físicas, pero también mentales ${ }^{5}$. Había que identificar a los "otros", a los diferentes, a esos que no servían para el modelo modernizador. En palabras de Zafaronni, las estadísticas socio-biológicas que encontraron un hombre medio, también identificaron al desechable orgánicamente, al "humano que no es persona", al enemigo interno, endógeno.

La propia estadística criminal, a partir del célebre belga Quételet, se valió de la construcción del concepto de hombre medio, una pretendida realidad que insensiblemente se convirtió en un ideal que, convenientemente manipulado, permitió considerar que el judío no era el hombre medio, que se apartaba de él, que no era ciudadano. En momentos en que produce un enorme revuelo la propuesta de un derecho penal del enemigo -y se pretende que hay humanos que no son personas- es 
revelador observar que la idea del hombre medio civilizado no sería más que un homúnculo surgido de la retorta de una alquimia criminológica, como instrumento útil para la fabricación de enemigos (Zafaronni, 2012).

\section{LA DEGENERACIÓN BIOLÓGICA DE LOS POBRES}

Esos enemigos, esas "no personas", son los degenerados, los sujetos que se alejan de la media estadística del "hombre medio", que se alejan de la norma prototípica y que, por tanto, son "anormales". Como es sabido, lo anormal, lo periférico, sufrirá un proceso de medicalización y de patologización hasta el punto de que, como nos explicó George Canguilhen (19041995), la diferenciación no se hará entre lo normal y lo anormal, sino entre lo normal y lo patológico (Canguilhen, 1986). Se trata de un proceso en el que la teoría de la degeneración desempeñó un papel fundamental que no podemos pasar por alto.

En 1895, año de la publicación de obras tan significativas como Les dégénérés de Valentin Magnan y Paul Maurice Legrain (1895), y Gli Anarchici de Cesare Lombroso (1895), la Revista Médica de Chile edita el ya citado Discurso de toma de posesión de Orrego Luco como presidente de la Sociedad Médica de Chile. Aun tratándose de la transcripción de una conferencia, debe considerarse, tanto por la categoría del disertante como por sus propios contenidos, uno de los textos más significativos, y seminales, del degeneracionismo en Chile (Sánchez, 2014).

Cuando comienza la segunda mitad del siglo XIX tienen lugar importantes cambios en el conocimiento de las ciencias biológicas. Alrededor de la publicación de El origen de las especies de Charles Darwin (18091882), la sociedad europea y americana va a reaccionar como temiendo las novedades que el evolucionismo hubiera podido presentar. Racismo antropológico, somaticismo médico, persecución del anormal o del extraño, etc., son algunas de las aportaciones que la ciencia positivista muestra. Los preludios de las crisis económicas y del liberalismo ponen en marcha, como ya hemos visto, mecanismos ideológicos que preparan el terreno. En este contexto, el médico dirigirá una dura mirada encaminada fundamentalmente a los criminales y a los enfermos mentales en un intento de dar soporte científico a las exigencias de la sociedad burguesa finisecular. Un buen ejemplo de ello fue la aparición del Traité des dégénérescences (1857), del alienista francés August
Morel, obra muy influyente que sentó las bases de la llamada doctrina de la degeneración (Huertas, 1987; Pick, 1989; Campos, Martínez y Huertas, 2000). El degeneracionismo fue, en muy buena medida, la respuesta que, durante la segunda mitad del siglo $\mathrm{XIX}$, dio la psiquiatría y la medicina legal a las necesidades de control social indispensables para mantener la hegemonía de las clases dominantes, sirviendo además de soporte para la génesis y desarrollo de otras teorías, como las de la escuela criminológica positivista italiana (Peset y Peset, 1975; Peset, 1983; Kneeper y Ystehede, 2012).

En su Discurso ${ }^{6}$, Orrego Luco, como presidente in pectore de la Sociedad Médica de Chile, se vale de conceptos degeneracionistas para argumentar sus propuestas de intervención social. Si como alienista entiende la degeneración de manera individualizada, en el individuo concreto, como médico-social percibe sus importantes implicaciones higiénico-sociales. Además, el papel de la herencia -elemento insoslayable en el discurso degeneracionista- otorga las claves necesarias para explicar las razones biológicas constitucionales -, de la desigualdad, para intervenir en familias y poblaciones enteras afectadas por las "taras hereditarias" $y$, sobre todo, para medicalizar el control de individuos y colectivos. Con una doble voluntad científica y política, pero también corporativa, Orrego reclama el monopolio ${ }^{7}$ médico de determinadas parcelas de la defensa social en las que otros agentes sociales, como abogados, educadores, etc., no tendrían cabida: "He dicho que hay en los dominios de la higiene un terreno cerrado para otros y abierto á nuestro estudio y propaganda. Me refiero, señores, á ese implacable y sombrío imperio de las leyes de la herencia" (Orrego Luco, 1895/2015, p. 64).

El sombrío destino de la herencia morbosa, de la herencia degenerada, implica incurabilidad, muerte y miseria biológica y moral, en tanto que se tiende a relacionar con enfermedades sociales como la sífilis o el alcoholismo. El pesimismo antropológico que caracteriza la teoría de la degeneración, queda bien patente en el discurso de Orrego cuando se refiere a la mortalidad infantil y a la sífilis congénita:

Todos los días estamos viendo mujeres que, en medio de la juventud, se ven condenadas á la forma de esterilidad más deplorable: -á la serie de los hijos muertos por infección hereditaria. Tienen hijos que mueren antes de nacer, hijos que mueren apenas han nacido; hijos que atraviesan la primera infancia en medio de una serie de accidentes patológicos, que van á sucumbir más tarde bajo la acción implacable de una infección hereditaria, á 
sufrir durante el curso entero de su vida el peso abrumador de aquella herencia sifilítica (Orrego Luco, $1895 / 2015$, p. 64).

La voluntad preventiva del médico no solo ante la amenaza venérea, sino ante la degeneración de la raza, le obliga a intentar intervenir, a través de la eugenesia y de la educación (y la propaganda), sobre una población potencialmente anormal:

Para que el niño viva, es necesario que la herencia no lo haya condenado á una muerte fatal é inevitable, es necesario que no muera antes de nacer. ¿No creéis, señores, que sería profundamente útil que vulgarizáramos con nuestros estudios el conocimiento de las leyes de la herencia, de las medidas necesarias para salvar a muchas madres de la enfermedad, á muchos hijos de la muerte, y á muchos padres de una desgracia que la vergüenza hace aún más amarga? (Orrego Luco, 1895/2015, p.66).

Resulta evidente que junto a las visiones más pesimistas y nihilistas que el degeneracionismo propicia, aparece una voluntad higiénica, más esperanzadora, que hace "totalmente compatible" -como ha señalado Marcelo Sánchez recientemente- "la puericultura y su afán preventivo, con las visiones hereditaristas más radicales; lo que establece más bien una continuidad, antes que una ruptura, entre la visión optimista de la puericultura y el ambientalismo con la creencia de un sistema de herencia fatídico y cerrado al cambio" (Sánchez, 2014, p. 385). Un planteamiento que, en efecto, puede identificarse en el discurso de Orrego Luco, pero que está presente ya en los primeros autores degeneracionistas pues, a pesar del peso indiscutible de la herencia en la etiología de la degeneración, el propio Morel remitía sus causas últimas a factores externos de carácter social (Huertas, 1993).

Especial interés tiene, en estas dinámicas preventivas, la preocupación de Orrego por las nodrizas:

Hay todavía otro punto á que sería tal vez oportuno llamar la atención pública. Sabéis, señores, que el niño sifilítico infecta á su nodriza y de ese hecho se deriva un nuevo peligro para la sociedad y un nuevo deber para nosotros.

Se ha buscado una mujer joven, fuerte, sana, para que sirva de nodriza de ese niño. Esa pobre mercenaria no sabe el peligro que corre; no sospecha, ni puede medir las consecuencias del servicio que va á desempeñar. Los padres de ese niño enfermo, tampoco miden la responsabilidad que ellos asumen (Orrego Luco, 1895/2015, p. 66).

La llamada lactancia mercenaria es, sin duda, un problema de salud pública que preocupa a higienistas y pediatras de todo el mundo a finales del siglo XIX (Navarro, 1982). Se trataba de una práctica extendida mediante la que familias aristocráticas y burguesas contrataban los servicios de nodrizas, mujeres puérperas procedentes, en general, del bajo pueblo que, habiendo perdido a su propio hijo o no, se encargaban de la alimentación y cuidados de los hijos de los niños de dichas familias. Como es lógico, las nodrizas eran cuidadosamente seleccionadas para que fueras mujeres sanas y fuertes, sin taras físicas ni morales. Se produce así una explotación y proletarización biológica de mujeres, de las que se obtiene una plusvalía orgánica. Sin embargo, como acabamos de ver, Orrego no desconfía de la mujer que ha de vender su leche materna, sino de sus empleadores, abogando por una serie de medidas que protejan:

Estamos, señores, en el deber de amparar á esa nodriza. No podemos hacernos la ilusión de que el resultado de nuestras discusiones pueda llegar á sus oídos, pero, en nombre de los deberes que la conmiseración humana nos impone, podemos crear una corriente de opinión que preste á esa mujer el amparo de la ley y podemos, sobre todo, despertar la conciencia social (Orrego Luco, 1895/2015, p. 66).

Con todo, y a pesar de voluntades higienistas e intentos reformadores, la amenaza de la degeneración termina relacionándose con la degradación y la inferioridad hereditaria del bajo pueblo:

Aquí encontramos una poderosa causa de mortalidad infantil; pero encontramos, sobre todo, el origen de afecciones que condenan á sus víctimas á una existencia más desesperante que la muerte misma, al idiotismo, á la demencia, á la perversión moral, á la neurosis que degradan al hombre, á tendencias criminales, que degradan á la especie (Orrego Luco, 1895/2015, p.67).

La relación entre el alcoholismo y la heredointoxicación alcohólica, causas degenerativas de primer orden (Huertas, 1993; Campos, 1997), y la criminalidad es una constante en el discurso médico y criminológico de la época (Huertas, 1993; Huertas y Martínez, 1993). Orrego lo expresa con mucha claridad cuando asegura que:

La influencia hereditaria del alcoholismo en la "embriología del crimen" es ya un hecho que no admite discusión. Á las vagas apreciaciones de épocas pasadas ha sucedido ahora una serie de trabajos documentados suficientes para formar un criterio irrecusable a este respecto (Orrego Luco, 1895/2015, p.67).

Una "embriología del crimen" que da lugar a familias marginales, y degeneradas, que amenazan y con- 
taminan una sociedad ordenada, pulcra y aséptica. El origen social de la criminalidad desaparece porque la biología lo invisibiliza, lo naturaliza:

Conoceis el célebre ejemplo, tantas veces citado, de la familia Yuke de Estados Unidos en que se contaron doscientos ladrones y asesinos, doscientos ochenta y ocho valetudinarios y noventa prostitutas, descendientes todos de un mismo tronco, el alcoholista Max, en el espacio de ciento quince años (Orrego Luco, 1895/2015, p.67).

Orrego está haciendo alusión a la célebre familia Juke, sobre la que Richard Louis Dugdale (1841-1883) publicó en 1877 The Jukes: a study in crime, pauperism, disease, and heredity, que llegó a convertirse en un clásico del eugenismo y cuya trama de decadencia, crimen y degeneración a través de generaciones, se solía sacar a la luz hasta bien entrada la década de 1930, especialmente en los debates sobre la esterilización eugénica (Sánchez, 2014, p. 386).

En todo caso, y como cabía esperar, cuando Orrego profundiza en su reflexión sobre el crimen y la criminalidad se muestra abiertamente lombrosiano:

Señores, sea cual fuere la manera como se aprecien las tentativas geniales de Lombroso, ellas han venido á establecer una serie de hechos que substancialmente modifican las hipótesis que servían de base á nuestras ideas sobre la criminalidad y la legislación penal.

En todo el mundo civilizado las doctrinas de Lombroso han tenido una profunda y viva resonancia, han modificado los procedimientos de la justicia criminal y modificado la organización del sistema carcelario (Orrego Luco, 1895/2015, p.68).

Orrego Luco, insta a la Sociedad médica a incorporar esta nueva criminología, dejando atrás la punición, comprendiendo e incorporando las novedades científicas y tecnológicas. Frente a las viejas leyes, que es preciso modificar, una nueva ciencia se alza como garante de la defensa social:

Señores, ya es tiempo que á ese movimiento científico se asocie el de los médicos chilenos; que nuestros estudios hagan ver cuál es el verdadero carácter de los hombres criminales, y que demostremos á nuestros legisladores que, á la vieja y bárbara teoría que veía en la pena un castigo impuesto al delito, es necesario substituir la noción más humana y más en armonía con la naturaleza de las cosas, que ha despojado á la pena de ese carácter de venganza, para ver en ella solamente una defensa de la sociedad en contra del crimen (Orrego Luco, 1895/2015, p.68).

Termina su disertación meditando sobre la joven raza americana. Frente a la vieja estirpe europea, ca- paz de generar "hombres de genio" o "degenerados superiores", las elites americanas deben estar dispuestas a recibir y adaptar los conocimientos producidos en otras latitudes:

Como ha observado el mismo Lombroso que acabo de citaros, mientras más vieja es una raza, en su degeneración misma encontrará más fuentes de neurosis y por consiguiente de genialidad, y al mismo tiempo una razón para que en su población encuentren resistencias los descubrimientos nuevos.

Esto nos explica el hecho contradictorio que pueblos que son en masa ultra-conservadores en política y en religión, sean los que han producido los más grandes revolucionarios en los diversos ramos de la actividad humana. Las razas nuevas no han desarrollado todavía en su seno esos gérmenes de degeneración de que brota la originalidad y el genio, no producen grandes revolucionarios religiosos y científicos, pero pueden, en cambio, apropiarse los descubrimientos y las ideas revolucionarias de los otros (Orrego Luco, 1895/2015, p.69).

En suma, las elites liberales del nuevo mundo estarías llamadas a importar conocimientos y destrezas con el fin de mejorar la raza y que las utopías tecnocientíficas sean posibles en nuevos territorios:

Y así, las nuevas ideas que salen de la vieja Europa, donde deban morir estériles, por falta, no de quién las crea, sino de quien las comprenda, irán á encontrar en el Nuevo Mundo quién las perpetúe fecundándolas y aplicándolas; así como el fruto inspirador de la vid, el primer consuelo y el primer pecado del patriarca asiático, principia á volvernos ya modificados y mejorados del Nuevo Mundo, donde por tanto tiempo pareció extraño(...) así como la libertad política, sueño utópico y envidiada meta del viejo continente, echa raíces sólidas y seguras en el mundo americano, de donde los grandes pensadores europeos recibirán nueva fuerza para sus trabajos y la última mirada de consuelo para una vida desconocida y burlada (Orrego Luco, 1895/2015, p.69).

En 1908, en vísperas del centenario de la independencia (1910) y algunos años más tarde de los discursos y escritos del Dr. Orrego Luco, se celebró en Chile, el Cuarto Congreso Científico (I Panamericano). Las dos secciones con mayor número de trabajos fueron, la de Ciencias Médicas e Higiene, dirigida por el médico chileno-alemán Germán Greve (1869$1854)^{8}$, y la de Ciencias Naturales, Antropología y Etnología, coordinada por el biólogo Carlos E. Porter (1867-1942) ${ }^{9}$. Es en este congreso donde el higienismo, la medicina, la etnología y las ciencias naturales se entrecruzan con más claridad, y donde la biometría se comienza a incorporar como una teoría y tecnología científica a seguir (Calvo, 2011, p.108). El nacio- 
nalismo y la identificación biológica habían triunfado, las elites latinoaméricas, habían incorporado estas tecnologías de depuración poblacional (bertillonage y dactiloscopia). El criminólogo chileno, Robustiano Vera (1844-1916), anunciaba en este Cuarto Congreso, una nueva amenaza, la de la inmigración no deseada, el último eslabón de la cadena teórica de la herencia degenerativa lombrosiana, el criminal político o revolucionario:

Los pueblos de América acrecientan su población por la inmigración. El beneficio es indiscutible. Si en cada puerto de entrada se establecieran gabinetes de identificación, no tendríamos tantos criminales, hay que defenderse de los agitadores, de los gremios obreros y de los anarquistas (Vera, 1909, p. 108).

Frente a anteriores oleadas inmigratorias, consideradas de manera positiva por la llegada de trabajadores y colonos europeos que iban a contribuir a la construcción de los estados nacionales y que dieron lugar consignas como la de "gobernar es poblar" del argentino Juan Bautista Alberdi (Vázquez, 1988), los inmigrantes europeos llegados al cono sur en el periodo comprendido entre 1870 y 1890 son percibidos de manera muy distinta. La derrota de la Comuna de París, la caída de la primera República española, las leyes antisocialistas de Bismarck y la dura represión de las revueltas obreras en Italia, fueron causas desencadenantes del traslado a América de contingentes de trabajadores con una activa militancia política a sus espaldas. Además, el proceso de industrialización dio lugar a una serie de problemas y tensiones sociales bien conocidas en Europa, pero que resultaban nuevos en el continente americano. La creación de sindicatos, "gremios obreros" como los denomina Robustiano Vera (1909), y en general el surgimiento del movimiento obrero (Pizarro, 1986; Ortiz, 2005), de corte socialista o anarquista, causó honda preocupación en las elites y precipitó tanto su criminalización como el desarrollo de estrategias y técnicas de defensa social. Unas elites que se preparaban para hacer frente a los "subversivos" y a las revoluciones sociales del siglo XX. Entre todo su arsenal, la ciencia no sería un arma menor.

\section{CONCLUSIONES}

Las observaciones científicas sobre el control social de la población, del psiquiatra chileno Augusto Orrego Luco, se sitúan en el marco de la industrialización y sus consecuencias. El discurso de Orrego se articuló no solo desde la teoría médica, pero con vocación de ser incorporado a políticas públicas y registros del Estado. Las modernas estadísticas biomédicas introducidas bajo la lectura racial y discriminatoria de las clases populares, ofrecieron herramientas para definir la anormalidad física y de las conductas, siempre mediante un claro determinismo biológico. La "otra raza" -asiática, mesoamericana, vagabunda, criminal y degenerada- fue etiquetada así por el Estado liberal, para iniciar un proceso de proletarización o regeneración obrera (la construcción del Homo hygienicus), lo que se correspondió con un programa higienista y eugenésico de "depuración" de la población en un modelo económico que exigía el modo de producción capitalista.

La teoría de la degeneración y su adaptación a la realidad chilena fue clave en la elaboración, por parte de Orrego Luco de su análisis sobre la cuestión social y de sus propuestas de intervención para construir la nueva colectividad que parecía necesitar el proceso de industrialización. La reproducción biológica de las masas obreras, sus enfermedades, el régimen alimentario, la influencia del clima o la geografía, etc., fueron los fenómenos biológicos estudiados por el médico chileno. Podemos concluir, pues, que Orrego Luco fue pionero de las reformas liberales en Chile, que fomentó a partir del lenguaje científico, una categoría de inferioridad biológica de los sectores populares, lectura positivista y racista, que perdurará y repercutirá en el discurso médico, y en la futuras políticas públicas conservadoras de la elite chilena. 


\section{NOTAS}

1 Ministro del Interior, desde el 26 de junio hasta el 25 de agosto de 1897; ministro de Justicia e Instrucción Pública desde el 14 de abril hasta el 18 de junio de 1898, bajo la administración de Federico Errázuriz Echaurren, y ministro de Justicia e Instrucción Pública, desde el 23 de diciembre de 1915 hasta el 8 de enero de 1916, bajo la administración de Juan Luis Sanfuentes Andonaegui. Véase Reseña Biográfica Parlamentaria: Augusto Antonio Orrego Luco. Historia Política Legislativa del Congreso Nacional de Chile [en línea], disponible en: http://historiapolitica.bcn.cl/resenas_parlamentarias/wiki/Augusto_Antonio_Orrego [consultado el 5/ 12/2018].

2 El propio Orrego Luco fue miembro de la Académie y llegó a colaborar en la Iconographie de la Salpêtrière, uno de los grandes proyectos de Charcot en el marco de sus estudios sobre la histeria. Véase Roa (1992).

3 Sobre el papel de los cambios climáticos y los fenómenos naturales, en el marco de la crisis de 1870, en la aparición de modelos (neo) coloniales muy agresivos y la aparición del "tercer mundo", véase Davis (2006).

4 Casi todas consideradas limitantes orgánicas de una población degenerada. INE, Instituto nacional de estadísticas (2009 p. 115)

5 En 1895, las estadísticas poblacionales chilenas incluían la enajenación mental, sutil dato para una nación que se desarrolla, pues establece una relación entre raza y patología mental. Véase INE (2009, pp. 114-115).

\section{BIBLIOGRAFÍA}

Araya, Alejandra (1999), Ociosos, vagabundos y malentretenidos. En Chile colonial, Santiago, DIBAM, p. 12.

Beaune, Jean-Claude (1983), Le vagabond et la machine. Essai sur l'automatisme ambulatoire. Médecine, Technique et société, 1880-1910, Seyssel, Champ Vallon, p. 185.

Calvo Isaza, Oscar (2011), “Conocimiento desinteresado y ciencia americana. El Congreso Científico (1898-1916)". Historia Crítica, 45, pp. 86-108, p. 108.

Campos, Ricardo (1997), Alcoholismo, medicina y sociedad en España 1876-1923, Madrid, CSIC.

Campos, Ricardo; Martínez, José; Huertas, Rafael (2000), Los ilegales de la naturaleza. Medicina y degeneracionismo en la España de la restauración (1876-1923), Madrid, CSIC.

Canguilhen, Georges (1986), Lo normal y lo patológico, México, Siglo XXI.

Caponi, Sandra (2013), "Quételet, el hombre medio y el saber médico", História, Ciências, Saúde - Manguinhos 20, pp. 831-847.

Carvajal, Yuri; Yuing, Tuillang (2013), “Las estadísticas de salud no nacen de un repollo: jesuitas, aritméticas políticas, estigmergias y oligópticos". Salud colectiva 9 (1), pp. 91-102.
6 Orrego Luco, Augusto (1895), “Discurso pronunciado por el doctor señor Augusto Orrego Luco. Al tomar posesión del cargo de Presidente de la Sociedad Médica", Revista Médica de Chile, 23 (2-3), pp. 52-60, reproducido en Leyton, César; Palacios, Cristián y Sánchez, Marcelo (2015) Bulevar de los pobres. Racismo científico, higiene y eugenesia en Chile e Iberoamérica, siglos XIX Y XX. Santiago, Ocho Libros editores. En lo sucesivo se cita por la paginación de esta última edición.

7 La teoría weberiana del "monopolio", íntimamente relacionada con otras categorías, como la de "clausura social", ha sido aplicada al estudio de las profesiones y, en particular, de la profesión médica. Una síntesis de los acercamientos metodológicos al estudio de las profesiones, puede encontrarse en González Leandri (1999).

8 Greve, realizó un peritaje a un criminal político, como fue denominado en la época a Antonio Ramón Ramón. Una metodología, que bordeaba entre la degeneración, el psicoanálisis y la antropología frenológica. Véase Sánchez (2014).

9 Greve, Germán (1909-1912) "Ciencias Médicas e Higiene", Trabajos de la V Sección. Tomo I.; y Porter, Carlos (19091912) "Ciencias Naturales, Antropologías y Etnologías." Trabajos de la III Sección. Tomo I. En Cuarto Congreso Científico Latinoamericano ( ${ }^{\circ}$ Panamericano), Volumen I, Santiago de Chile, Imprenta y Litografía y Encuadernación Barcelona.

Castel, Robert (1995), La metamorfosis de la cuestión social: Una crónica del salario, Buenos Aires, Paidós, p. 97.

Cruz-Coke, Ricardo (1995), Historia de la medicina, Santiago, editorial Andrés Bello.

Davis, Mike (2006), Los holocaustos de la era victoriana tardía. El niño, las hambrunas y la formación del Tercer Mundo. Valencia, editora Universidad de Valencia.

De Gaudemar, Jean-Paul (1979), La mobilisation générale, Paris, Éditions du Champs Urbain, p. 39.

De Salas, Manuel (1804), Oficio de la diputación del hospicio al Excmo. Señor don Luis Muñoz De Guzmán, gobernador y capitán general del reino, don Luis en que se proponen medidas para arbitrar recursos con que sostener el establecimiento por Manuel de Salas 1804. En: Grez, Sergio (1995), La cuestión social en chile. Ideas y debates, precursores (1804-1902) Santiago, DIBAM, pp. 45-50, p.45.

Durou, Bernard (1966), Vagabonds et Clochards : étude biologique, psychopathologique et sociale du vagabondage, Toulouse, Agen, p. 31.

Ellul, Jacques (1965), “¿Existe el 'hombre medio' desde el punto de vista sociológico?" Revista de Estudios Políticos 144: 25-46. 
Fecteau, Jean Marie (2004), La liberté du pauvre. Crime et pauvreté au XIXe siècle québécois, Montreal, UBL éditeur.

Goic, Alejandro (1992), Ensayo sobre la educación médica en Chile 1933-1990. Entre la autonomía y la intervención, Santiago, Editorial Universitaria, p. 10.

Góngora, Mario (1966), "Vagabundaje y sociedad fronteriza en Chile. (Siglos XVII y XIX)". Santiago, Cuadernos del Centro de Estudios Socioeconómicos 3, (2).

González Leandri, Ricardo (1999), Las profesiones: Entre la vocación y el interés corporativo. Fundamentos para su estudio histórico, Madrid, Catriel.

Hacking, Ian (1998), Mad Travelers. Reflections on the Reality of Transient Mental IIlnesses. Charlottesville \& London, University Press of Virginia.

Huertas, Rafael (1987), Locura y degeneración. Psiquiatría y sociedad en el positivismo francés, Madrid, CSIC.

Huertas, Rafael (1988), Orfila. Saber y poder médico, Madrid, CSIC, p. 76.

Huertas, Rafael (1993), "Entre el nihilismo terapéutico y la higiene social: la asistencia psiquiátrica en el positivismo francés". En: Ángel González de Pablo (ed.), Enfermedad, clínica y patología. Estudios sobre el origen y desarrollo de la medicina contemporánea, Madrid, Ed. Complutense, 301-314.

Huertas, Rafael (1993), "Madness and degeneration, II. Alcoholism and Degeneration". History of Psychiatry 4, pp. 1-21.

Huertas, Rafael (1993), "Madness and degeneration, III. Degeneration and Criminality". History of Psychiatry 4, pp. 141-158.

Huertas, Rafael; Martinez, José (1993), “Disease and crime in Spanish positivist psychiatry". History of Psychiatry 4, pp. 459-481.

Huertas, Rafael (2008), Los laboratorios de la norma. Medicina y regulación social en el Estado liberal, Barcelona, Octaedro.

Huertas, Rafael (2014), “Les aliénés voyageurs. La médicalisation de l'errance durant la fin-de-siècle". Cahiers des Amériques - Figures de l'Entre 4, pp. 123-138.

Instituto Nacional de Estadísticas (INE) (2009), Formando identidad nacional, Censos de Población en el Chile republicano. En retratos de Nuestra identidad: $Y$ su evolución histórica hacia el Bicentenario, Santiago. INE

Illanes, María Angélica (2010), En el nombre del pueblo, del estado y de la ciencia: historia social de la salud pública, Chile, 1880-1973; hacia una historia social del siglo XX, Santiago de Chile, Colectivo de atención primaria.

Kneeper, Paul; J. Ystehede, Per (2012) (eds.), The Cesare Lombroso Handbook, United Kingdon, Routledge.

Lombroso, Cesare (1895), Gli Anarchici, Turín, Fratelli Brocca.

Magnan, Valentin; Legrain Paul Maurice (1895), Les dégénérés. Etat mental et síndromes épisodiques, Paris, Rueff.

Marx, Karl (2008), La lucha de clases en Francia de 1848 a 1850 [en línea], disponible en: https://pensaryhacer.files.wordpress.com/2008/08/la-luchade-clases-sociales-en-francia-1848-1850.pdf.

Marx Karl (2011), El XVIII Brumario de Luis Bonaparte, Buenos Aires: Editorial Claridad.

Morel, August (1857), Traité des dégénérescences physiques, intellectuelles et morales de l'espece humaine et des causes qui produisent ces variétés maladives, Paris, J.B. Baillère.

Navarro, Pedro (1982), “Lactancia mercenaria: otra expresión de la doble moral burguesa". Asclepio 34, pp. 33-70.

Larraín Aguirre, Camilo (2002), La sociedad médica de Santiago y el desarrollo histórico de la medicina en Chile, Santiago, Sociedad Médica.

Leyton, César; Huertas, Rafael (2012), “Reforma urbana e higiene social en Santiago de Chile. La tecno-utopía liberal de Benjamín Vicuña Mackena (1872-1975)", Dynamis, 32 (1), pp. 21-44.

Leyton, César; Palacios, Cristián; Sánchez, Marcelo (2015) (eds.), Bulevar de los pobres. Racismo científico, higiene y eugenesia en Chile e Iberoamérica, Siglos XIX y XX. Santiago, Ocho Libros editores.

Orrego Luco, Augusto (1897), La cuestión Social, Santiago, Imprenta Barcelona.

Ortiz, Fernando (2005), El Movimiento Obrero en Chile. 18911919, Santiago, Editorial Lom.

Peset, José Luis; Peset, Mariano (1975), Lombroso y la escuela positivista italiana, Madrid, CSIC.

Peset, José Luis (1983), Ciencia y Marginación. Sobre negros, locos y criminales, Barcelona, Crítica.

Pick, Daniel (1989), Faces of Degeneration. A European Disorders, c.1848-c.1918, Cambridge, Cambridge University Press.

Pizarro, Crisóstomo (1986), La huelga obrera en Chile. 18901970, Santiago, Ediciones SUR.

Quételet, Adolphe (1827), Recherches sur la population, les naissances, les décès, les prisons, les dépôts de mendicité, etc., dans le royaume des Pays-Bas, Bruselas, Chez Tarlier.

Quételet, Adolphe (1835), Sur l'homme et le développement de ses facultés, ou Essai de physique sociale, Paris, Bachelier.

Ramírez, Susana (2002), La salud del Imperio. La Real Expedición Filantrópica de la Vacuna, Madrid, Doce calles.

Roa, Armando (1992), Augusto Orrego Luco en la cultura y medicina chilena, Santiago, editorial Universitaria.

Rosen, George (1985), De la policía médica a la medicina social: ensayos sobre la historia de la atención a la salud, Madrid, editorial Siglo XXI.

Salinas, Maximiliano (1986), "El bandolero chileno del siglo XIX. Su imagen en la sabiduría popular", Araucaria de Chile, 36, pp. 57-75.

Sánchez, Juan (1999) “Quételet y la Sociología”, Revista Española de Investigaciones sociológicas 87, pp.291-304. 
Sánchez, Marcelo (2014) "La teoría de la degeneración en Chile (1892-1915)”, Revista de Historia 2, (47), pp. 375-400.

Vaschetto, Emilio (2010), Los Descarriados. Clínica del extravío mental: entre la errancia y el yerro, Buenos Aires, Grama ediciones.

Vázquez, Horacio (1988), “La Constitución poblacionista de Argentina de 1852", Asclepio 40 (2) pp.267-285.

Vázquez, Francisco (2009), La invención del racismo. Nacimiento de la biopolítica en España. 1600-1940, Madrid, Akal.

Vera, Robustiano (1909), IV Congreso Científico ( $1^{\circ}$ Panamericano): celebrado en Santiago de Chile el 24 de diciembre de 1908: trabajos presentados a dicho congreso por el Delegado de las Repúblicas de Honduras y Nicaragua, Santiago de Chile, Imprenta y Encuadernación Gálvez, 158.

Vicuña Mackenna, Benjamín (2013), "La policía de seguridad en las grandes ciudades modernas (Londres, Paris, Nueva York, Santiago)", Santiago, Imprenta de la República de Jacinto Núñez, p. 26. En: Cristián Palacios; César Leyton (eds.), Industria del delito. Historias de las ciencias criminológicas en Chile, Santiago, Ocho libros, pp. 89-122.

Zafaronni, Raúl (2012), “Introducción a Criminología, civilización y nuevo orden mundial en Wayne Morrison", Revista Crítica Penal y Poder 2, pp. 1-17. 